\title{
Research on Graduation Design Innovation Under the Dual Drive Models of "Internet Plus" and "Transformation of Local Colleges and Universities"*
}

\author{
Qinghai Wang \\ Computer College \\ Qinghai Normal University \\ Xining, China 810008
}

\begin{abstract}
In the context of the dual drive models of "Internet plus" and "transformation and development of local colleges and universities", this paper takes Qinghai Normal University's transformation to application-oriented comprehensive university as an example, expounds the new measures brought by ZTE's ICT production and education integration and innovation base project in school-enterprise cooperation. Combining the different perspectives of Internet, Internet of Things, artificial intelligence, machine learning, cloud computing and other emerging platforms, this paper explores the profound changes in "Internet plus" and the teaching mode of applied universities, and puts forward the practice and innovation ideas for the graduation design of "Internet plus" and applied universities. The undergraduate design innovation model of five-integrated application-oriented university from the new teaching mode, comprehensive practice innovation, student graduation design, personal ability improvement, and career planning layout is constructed.
\end{abstract}

Keywords-higher education; Internet plus; practice and innovation; transformation of colleges and universities

\section{INTRODUCTION}

In the history of the development of human society, every major invention of new technology will promote major changes in human civilization. At the same time, it brings great changes to education, especially higher education, promoting the iteration of educational ideas, the increase of education content, and the upgrading of educational methods [1].

With the rapid development of core technologies such as the Internet, Internet of Things, cloud computing, and big data, the fields of "Internet $+"$ economy and society are deeply integrated. Through the promotion of technological progress, efficiency improvement and organizational change, the innovation and productivity of the real economy have been improved. It forms a new form of economic and social

* Fund Projects: Key Project of Qinghai Normal University Teaching Research (qhnujy2015102); Project of Qinghai Provincial Science and Technology Department (2017-ZJ-768); Next Generation Internet Innovation Project (NGII20160504); Project of Chunhui Planning of Ministry of Education (Z2015051); National Social Science Project (17XTQ013).

CLC number: G 642. 477 Document code: A development with broader Internet-based infrastructure and innovation elements.

"Internet + education" is an important part of the national strategy "Internet + ", a pioneer and cutting edge in the reform and development of education, and a powerful engine for accelerating the process of educational modernization [2]. "Internet + education" makes full use of digital education resources and education service platforms, online course resource sharing, large-scale online open courses and other new learning models, connects online and offline education resources, expands the coverage of quality education resources, and promotes educational equity. The essence of "Internet + education" is technology integration education, the inheritance optimization and model upgrade, the supplement, auxiliary and development of traditional education. It is the customization, flexibility and individualization of education under the information support and push environment [3].

\section{The CONTINUOUS AdVANCEMENT OF THE DEEP INTEGRATION OF "INTERNET + HIGHER EDUCATION"}

As an important communication place for the knowledge culture created by mankind, higher education institutions are training base for senior professionals, and have its own inherent laws of development. With the deep integration of the Internet and higher education, traditional higher education breaks the geographical and time-space boundaries in this information technology revolution, providing unprecedented new time and space for modern higher education. The organizational system, teaching content and teaching methods of traditional higher education, and quality evaluation and student learning patterns have significant changes. Big data, cloud computing and mobile internet in the context of the Internet have become an important force in the transformation of higher education. In this context, the connotation of "Internet + higher education" is to break through the geographical and temporal boundaries of the higher education model. It is based on the advantages of big data resources, and the deep integration of the Internet and higher education, embedding and overlapping each other. It reconstructs the new organizational ecology, development model and corresponding curriculum system, teaching 
system, learning system and evaluation system of modern higher education. It realizes the reproduction of the organization process of Internet + modern higher education, and promotes the value transfer, value sharing and value creation of the world's higher education resources [4].

The development of Internet + higher education needs to have overall consideration from profound changes in the structure, scale, quality and efficiency of traditional higher education, the resource elements of traditional higher education, the higher education systems of various regions, and the components of higher education systems. The traditional higher education development model based on the prediction and planning of traditional markets is also facing tremendous changes in the new era. The "Internet+" has spawned many new industries, and the Internet + society has diversified work forms. It also has proposed more needs for various types of applied talents. To better cultivate various types of applied talents and better serve the society in the new era requires new development of higher education in the new era. The boundlessness of Internet + higher education resources, the cultivated diversity of talents, the innovation of learning models, the systematic adjustment of structure, and the sharing of high-quality resources all require shortening the response cycle of higher education to social change and fostering senior talent.

In summary, in the context of the "Internet + " plan, the sustainable development and steady advancement of the deep integration of "Internet + higher education" is an inevitable trend of higher education development.

\section{THE PATH SELECTION OF SCHOOL-RUNNING ORIENTATION IN THE LOCAL UNIVERSITY'S TRANSFORMATION TO APPLICATION-ORIENTED UNIVERSITY}

In order to improve the ability and level of local colleges and universities serving regional economic and social development, the Party Central Committee and the State Council have made decision-making arrangements for the transformation of some local ordinary undergraduate colleges into applied applications. In 2015, the Ministry of Education formulated the "Implementation Opinions of the Transformation of General Undergraduate Universities to Application-oriented Universities". In March 2016, Qinghai Provincial Government issued a comprehensive education reform plan for Qinghai Province. In order to further improve the reform of higher education in Qinghai Province, it is necessary to clarify the orientation of running schools, consolidate the characteristics of running schools, adjust disciplines, deepen education and teaching reform, optimize talent training mode, and strengthen innovative entrepreneurship and practical teaching links, vigorously cultivate applied, compound, technical and skilled talents, and actively serve industry transformation and upgrading and economic and social development. It promotes the transformation of Qinghai University, Qinghai Normal University and Qinghai University for Nationalities into application-oriented and comprehensive universities, improves the level of education and innovation, highlights the characteristics, and enhances the comprehensive strength of running a school.
In order to achieve the goal of establishing an application-oriented comprehensive university, better serving the society, and cultivating industrial applied technical talents, Qinghai Normal University has actively carried out school-enterprise cooperation projects. In July 2016, it was successfully selected as the partner institution to participate in "Ministry of Education — ZTE ICT Production and Education Integration and Innovation Base Project". The "Ministry of Education - ZTE ICT Production and Education Integration and Innovation Base Project" is mainly characterized in the substantial transformation of local universities and the integration of production and education, and plays a role in demonstration. The base will be jointly organized by the teaching team with rich industry work experience and the cooperative colleges to jointly develop talent training programs and teaching materials, build a practical teaching platform, develop teaching resource pools, train dual-teachers, and provide student employment support. They will integrate the resources of universities, industries and enterprises to implement school-enterprise cooperation, integration of production and education, and collaborative education, and cultivate the application-oriented technical talents urgently needed for regional economic development.

The base has been in operation since September 2016. Currently, it has two majors: "Internet of Things Project" and "Electronic Information Engineering (Communication)". Currently, there are 304 students in 2 sessions. The base laboratory adopts the mode of school-enterprise joint construction and management. Qinghai Normal University and ZTE jointly invested industrial equipment of 13.4 million covering the cooperative professional group as the base experimental equipment. These industrial equipment mainly includes 4G LTE wireless communication system platform, communication basic network platform (passive optical access network system XPON, data communication system, optical transmission system, enterprise-level softswitch platform, video conference system, video surveillance system, communication engineering construction training system, communication power system), IoT scenario-Smart transportation application system (highway ETC non-stop toll system, highway ambiguous path identification system, BRT function bus system, open function parking system, RFID electronic license plate system), and cloud computing platform, providing rich and varied experimental platform for students and teachers. Through the education of professional quality for college students, it can improve the overall quality of students, and implement innovation and entrepreneurship education and the innovative entrepreneurship projects. The student learning model is implemented from the new generation of information technology "smart learning workshop system", giving full play to the rich enterprise work experience of the enterprise engineer lecturers, implementing the independent teaching of the engineers, and improving the students' practical ability. The enterprise regularly organizes school teachers to participate in enterprise engineer training and actively implements double-teacher training. New students enrolled in the employment service agreement to ensure the employment rate of students. 
The concept and measures of school-enterprise cooperation in running schools provide an effective path for the transformation, professional development, personnel training and social service of local colleges and universities, especially those in underdeveloped western regions.

\section{PROFOUND CHANGES IN THE TRADITIONAL TEACHING OF INTERNET + APPLIED UNIVERSITIES}

With the advent of new era of integration of production and education, from school-enterprise cooperation to relying on enterprises to embracing the industry, from integrating enterprise resources to integrating industry resources, higher education pays more attention to the improvement of education quality, and uses information technology to achieve intelligent learning. The latest industry technology is transformed into educational technology to enhance professional teaching and learning efficiency.

\section{A. New Learning Methods Based on Smart Learning Factory}

The new learning model based on smart learning factory demonstrates the new generation of educational information technology from the aspects of changing student learning methods, teaching methods, professional management methods, education big data analysis, link and sharing, presentation and experience, and has the characteristic of teaching information management. It changes the original education informationization practice mode of schools, and carries out Internet + education innovation and practice from the aspects of professional, learning and teaching. As the core scene of the school, the smart learning factory will shift from the relative separation of the basic teaching scenes to the relative integration of the spatial and technical dimensions, and promote the re-engineering of the talent cultivation process and the reorganization and upgrading of campus space structure. Relying on industry and enterprise resources, the digital professional curriculum resource system based on international engineering education standards is on the basis of school-enterprise cooperation. The industry and education are integrated. And professional curriculum resource system conforming to international professional certification standards is developed. Curriculum resources present significant features: digitization, engineering case base, sitcoms, knowledge and skill maps, and mission scenarios. It changes professional management methods and teaching methods.

\section{B. New Learning Methods Based on MOOC}

The emergence of Massive Open Online Courses (MOOCs) has created digital tsunami in the field of distance education. It has had huge impact on traditional higher education, and has led to the thinking and hot discussion on teaching model, education resources and quality of traditional higher education [5][6][7][8]. MOOC reflects the new way of "online learning sharing". People can have the highest quality of online courses that organizing knowledge and learning processes in new ways, regardless of time and space. The essence is to maximize the large-scale learning and sharing of the best resources of famous teachers by opening online quality course resources worldwide [9].

\section{New Teaching Mode Based on Cloud Computing and Big Data}

In the era of big data, the informatization of higher education has shifted from the original emphasis on software services and platform services to a new model that emphasizes data services. Education big data makes learning behavior, learning status, learning outcomes and other educational information capturable, quantifiable and transferable. Tablets, smart phones, various sensors, wearable devices, and radio frequency identification (RFID) tags can be used as automatic data collectors and used in all aspects of teaching, making smart campuses and classrooms a reality. It makes accurate teaching, personalized push, and doubtful solutions more precise and feasible.

\section{New Teaching Mode Based on Artificial Intelligence}

"Internet + artificial intelligence" refers to providing artificial intelligence public innovation services based on the Internet platform, accelerating the breakthrough of artificial intelligence core technology, improving the promotion and application of artificial intelligence in many fields, cultivating a number of key enterprises and innovation teams leading the development of global artificial intelligence, and forming innovative, open, cooperative, and collaborative development of the industrial ecology [10]. Through personalized learning customization, and the information collection of enough students, big data can describe the learning characteristics of each student, providing sufficient basis for personalized teaching. And it uses the processing power and analytical capabilities of artificial intelligence to create personalized learning experience process for each student. When students browse the course materials and answer relevant questions, the intelligent learning system will give relevant learning content and adjust in real time according to the students' mastery of knowledge and learning progress. Machine learning and virtual reality will bring each student specific knowledge and service recommendations.

\section{THE PRACTICE INNOVATION OF THE GRADUATION DESIGN OF THE INTERNET + APPLICATION UNIVERSITY}

\section{A. Conceptual Innovation}

Under the background of Internet + local university transformation + higher education, the artificial intelligence creation + graduation design, machine learning platform + graduation design, cloud computing framework + graduation design, big data + graduation design and other frameworks and the birth of new things have ushered in an innovative era of ideas and thinking for the graduation design of higher education undergraduates.

\section{B. Topic Innovation}

Internet + higher education offer unprecedented opportunities and changes. Applied undergraduate design and practice also brings new choices and innovation. From the supervised learning represented by the combination of 
AlphaGo neural network (NN) implementation strategy network and value network and Monte carlo search (MCTS) artifact, to the updated version of self-learning and reinforcement learning of AlphaGo Zero, a new perspective of artificial intelligence (AI) application has been unveiled. Artificial intelligence + various applications have become a new application and research hotspot. Artificial intelligence + application have become a new choice and new thinking of graduation design practice.

In the perspective of machine learning $(\mathrm{ML})+$ various applications, the use of various intelligent algorithms has become easier and more convenient, and data analysis and visualization have new explanation of complex problems. Multi-platform cloud computing services (Baidu, Amazon, and WeChat) provide a new model for various application development and efficient use of cloud resources. Cloud storage and cloud computing can be customized and serviced, and can be used for various data through public interfaces. The data is mined and analyzed to obtain credible and effective conclusions in a timely manner.

\section{Model Innovation}

Under the new background of Internet + application + higher education, the development of colleges and universities will pay more attention to internal structure optimization, integration of high-quality resources to strengthen the connotation development. Through new teaching modes, innovative learning models, student graduation design, personal ability development, career planning and layout, it builds a five-in-one graduation design innovation model, and strengthens the cultivation of talented and applied talents.

- Mode 1 Constructing five-in-one innovative design models for school-enterprise cooperation, practice innovation, graduation design, employment services, and collaborative management.

- Mode 2 Constructing five-in-one innovative design pattern of smart workshops, comprehensive practice, graduation design, skill training, and teaching collaboration.

- Mode 3 Constructing five-in-one innovative design model of dual-teacher linkage, platform innovation, graduation design, quality expansion, and career planning.

- Mode 4 Constructing five-in-one innovative design model of AI+ML, regional feature mining, graduation design, social service, and collaborative innovation.

The above models all reflect the individualized choice of knowledge communication and student learning, the customization changes of personal skills training environment, the integration of personal career development planning and graduation design innovation in the context of Internet + applied universities. It needs to cultivate and shape the innovative and practical talents in the era of new information.

\section{Platform Innovation}

From the perspective of artificial intelligence (AI) and machine learning (ML), the introduction of many machine learning platforms represented by TensorFlow provides new solutions and means for people to solve practical problems by using machine learning models and algorithms. From the perspective of cloud computing, Amazon, Baidu, and Ali have launched convenient and effective cloud computing platforms to provide various cloud storage services, cloud computing services and multi-platform collaboration solutions. From the perspective of regional characteristics, with the deep integration of the Internet + industry, various resources and products with regional characteristics have brought more demands and applications. From the perspective of big data, efficient distributed storage, calculation and analysis have become the current research and application hotspots. Based on the Hadoop ecosystem and its architecture, the actual development and application of Map Reduce, Storm and Spark programming model are used in big data distributed storage environments such as HDFS and HBase.

\section{CONCLUSION}

To sum up, on the one hand, the deep integration of the Internet and higher education has provided unprecedented new time and space and new challenges for traditional higher education, which has given birth to a new pattern of modern higher education. On the other hand, the cooperation between schools and enterprises, the establishment of multicooperative mechanism to form a system of integration of production and education is becoming an inevitable trend in the transformation path of local universities. In this dualdrive mode, the article takes the transformation and development of Qinghai Normal University as an example, and expounds the new measures brought by ZTE's ICT production and education integration and innovation base project in school-enterprise cooperation and education. From different perspectives of emerging platforms such as the Internet, Internet of Things, artificial intelligence, machine learning, and cloud computing with the rapid development, it has put forward practical and innovative ideas for the graduation design of Internet + applied universities, and constructed five-in-one application-oriented undergraduate graduation design innovation model of new teaching model, comprehensive practice innovation, student graduation design, personal ability improvement, and career planning layout.

\section{REFERENCES}

[1] $\mathrm{Xu}$ Fei. In the era of artificial intelligence, universities should transfer to "study as the center". Wenhui Bao. 2018-06-25, (1).

[2] Qin Hong, Zhang Wusheng. The essential characteristics and development trend of "Internet + education"[J]. Educational Research 2016,37(06),8-10.

[3] Zhang Yantong, Zhang Yan. The essence and connotation of "Internet + education" [J]. National Academy Of Education Administration, 2018 (01), 62-68. 
[4] Wen Jun. The internationalization development of higher education under the vision of "Internet +"[J]. Theoretical Perspectives. 2017-05: 22-24.

[5] Wang Zuoli. MOOC: making the education pattern more open [J]. China Education Network. 2014( 1) : 22.

[6] Jiao Jianli. MOOC: university opportunities and challenges [J]. China Education Network. 2013(4) : 21-23.

[7] Yang Yuanyuan. Teaching model innovation in the era of MOOC [J]. College Education. 2014( 7):49-51.

[8] Yang Jinsong, Xie Shuangyuan, Zhu Weiwen et al. MOOC: A new model for the integration and sharing of knowledge resources in universities [J]. Higher engineering education research. 2014( 2) : 8588.

[9] Lin Lijun. Whether "MOOC" can incite the reform of China's higher education [N]. Science and Technology Daily. 2013-10-15( 03).

[10] Zhou Jing, Wang Xiaonan. Research on information technology teaching mode in artificial intelligence age[J]. Computer Education. 2017(12): 109-112. 